\title{
Studies of Vaporization of Polyethylene Oligomers Using Gel-Permeation Chromatography
}

\author{
Akira Kotera, Kunio Furusawa, and Hiromichi Noguchi \\ Department of Chemistry, Tokyo Kyoiku University, \\ Otsuka, Tokyo, Japan.
}

(Received March 11, 1974)

\begin{abstract}
Vaporization of polyethylene oligomers was studied in a high vacuum $\left(\sim 10^{-7} \mathrm{mmHg}\right)$ between 220 and $450^{\circ} \mathrm{C}$. The results were analysed by determining the molecular weight and the molecular weight distribution of vaporized and residual polymer, using gel permeation chromatography. The molecular weight of the vaporized material increased as the temperature of vaporization rose, and a molecular vaporization ceiling of $c a .1500$ in molecular weight was found. The results were discussed and explained successfully in terms of the equation of state based on the hole theory given by Kurata, et al., and the theory of depolymerization kinetics with vaporization by Simha, et al.
\end{abstract}

KEY WORDS Vaporization / Degradation / Critical Chain Length / Polyethylene Oligomer / Gel-Permeation Chromatography / Thermal Stability /

It has been widely agreed that polymer molecules do not vaporize, but decompose on heating. However, it is reasonable to assume that polymer molecules must have a vapor pressure, even through this will be very faint, and that it must be possible to vaporize the molecules under suitable conditions in which decomposition does not make appreciable progress. Some attempts have been made using linear polyethylene samples, as it is well known that the methylene groups have less cohesive energy than the other groups. Miyoshi, et al., ${ }^{1}$ reported that polyethylene, when heated in a vacuum $\left(\sim 10^{-5}\right.$ $\mathrm{mmHg}$ ), gave off a film-like material and the molecular weight of this material was determined later as $\sim 500$ by Takizawa, et al. ${ }^{2} \mathrm{~S}$. L. Madorsky, et al., ${ }^{3}$ have conducted similar experiments during the course of polymer pyrolysis in a vacuum $\left(\sim 10^{-5} \mathrm{mmHg}\right)$, using a mass spectrometer, and have shown that the molecular weight of the largest volatile polyethylene molecule in a temperature range of $405-431^{\circ} \mathrm{C}$ is 692. The number of carbon atoms of the largest molecule was later called the critical chain length by $\mathrm{R}$. Simha, et $a .^{4} \quad$ A very valuable contribution has been made by L. A. Wall, et al, ${ }^{5}$ who examined the vaporization kinetics of pure $n$-alkanes up to $\mathrm{C}_{94} \mathrm{H}_{190}(M=1318)$ by a gravi- metric method. They have confirmed that the vaporization of $n$-alkanes, comprising $c a .100$ carbon atoms, is possible without any thermal degradation. These results suggest that the maximum size of a species capable of molecular vaporization without decomposition is greater than previously believed.

The present work is an experimental study on the thermal behavior of polyethylene oligomers during both vaporization and degradation. Vaporization was carried out in a high vecuum $\left(\sim 10^{-7} \mathrm{mmHg}\right)$ to minimize thermal degradation, using a specially constructed vacuum vessel. The molecular weight and molecular weight distribution of polyethylene oligomers obtained as vaporized and as residual materials were determined by gel permeation chromatography. The results were analysed by the equation of state given by Kurata, et al., ${ }^{6}$ based on the hole theory.

\section{EXPERIMENTAL}

Polyethylene Samples used in the present study were commercial polyethylene wax (AC-615) and Marlex-50 (Type-35). AC-615 was purchased from Allied Chemical Corporation, U.S.A., and the number-average molecular weight $\left(M_{n}\right)$ was 


\section{A. Kotera, K. Furusawa, and H. Noguchi}

determined by ebulliometry to be $2.8 \times 10^{3}$. The $\mathrm{CH}_{3} / \mathrm{CH}_{2}$ ratio which expresses the degree of chain branching was measured by infrared absorption technique ${ }^{7}$ and determined to be $2.84 \%$ for the AC-615. This value shows that the amounts of branching included would be relatively small because, for an idealized linear polyethylene of $M_{n}=2.8 \times 10^{3}$, the ratio amounts to $1 \%$ of the methyl groups at the molecule ends. The other structual units such as unsaturation have also been shown to be less than $0.5 \%$. Marlex polyethylene has essentially no branching and the number-average molecular weight was determined to be $11.0 \times 10^{3}$. These samples were employed without further purification.

A Vaporization Vessel was constructed in our laboratory, which was similar to the cell that Madorsky $^{3}$ used in his pyrolytic fractionation experiment, but with some modification. The vessel is shown diagramatically in Figure 1a. The distance between the sample and the condensing surface is $30 \mathrm{~mm}$, and the diameter of the condensing surface is $50 \mathrm{~mm}$. The surface was cooled by liquid nitrogen below $-100^{\circ} \mathrm{C}$ to minimize the decomposition of the vaporized material. The cooling by liquid nitrogen also was useful to keep the vessel at a constant vacuum for the period needed to conduct the vaporization experiments.

(1 a)

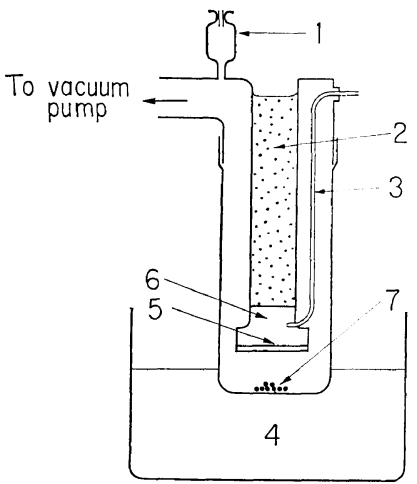

Figure 1. Diagrammatic sketch of the vaporization vessels: (1a), Madorsky type of cell; (1b), a cell to determine the weight fraction of vaporized sample; 1, ionization gauge; 2, liquid nitrogen; 3 , thermocouple; 4 , heat bath $\left(\mathrm{KNO}_{3}: \mathrm{NaNO}_{3}=\right.$ $1: 1) ; 5$, pyrex glass plate; 6 , copper connecter; 7 , polyethylene sample.
A different type of vessel, shown in Figure $1 \mathrm{~b}$, was employed to determine the weight of the vaporized material in relation to the amount of the original sample. The cell was constructed of several subchambers divided by slender necks, so that the vaporized materials produced by the decomposition of the sample were trapped in the vessel and deposited in the upper chambers, except for the noncondensing materials.

The Vaporization Experiments were carried out under a pressure of $5 \times 10^{-7} \mathrm{mmHg}$; a diffusion pump with silicon oil was used to evacuate the vessel. An ionization gauge located at the top of vessel usually indicated a constant pressure throughout the experiments, but in the case where the second-type of cell was used the gauge indicated a lower degree of vacuum as the vaporization went on. The thermostat of $\mathrm{KNO}_{3}-\mathrm{NaNO}_{3}(1: 1)$ was used to keep the temperature of the vessel within $0.1{ }^{\circ} \mathrm{C}$. The experiments were conducted for $30-60 \mathrm{~min}$ isothermally between 220 and $460^{\circ} \mathrm{C}$.

The weight of the vaporized material in relation to the amount of the original sample was determined as follows: The weighed polyethylene $\left(W^{\circ}\right)$ was put in the lowest chamber of the cell of Figure $1 \mathrm{~b}$ and subjected to vaporization for 30-60 min, depending on the temperature of the experiments. The cell was then cut off from the vacuum line and separated at the lowest neck into two parts, which held the vaporized $\left(W^{v}\right)$ and residual materials $\left(W^{\mathrm{r}}\right)$ respectively. Both parts were weighed separately and the weight fractions of the vaporized $\left(f^{\mathrm{v}}=W^{\mathrm{v}} /\left(W^{\mathrm{v}}+W^{\mathrm{r}}\right)\right)$ and the residual $\left(f^{\mathrm{r}}=W^{\mathrm{r}} /\left(W^{\mathrm{v}}+W^{\mathrm{r}}\right)\right)$ materials were calculated. Finally, the difference between the weight of the original sample $\left(W^{\circ}\right)$ and the sum of those of the two parts $\left(W^{\mathrm{v}}+W^{\mathrm{r}}\right)$ was calculated and the amount of noncondensing material produced by decomposition, i.e., the weight loss $\left(W^{\circ}-\left(W^{\vee}+W^{\mathrm{r}}\right)\right)$ was determined.

Gel-Permeation Chromatography (GPC). Water's Model 200 was used to determine the molecular weight and the molecular weight distribution of the original samples and also of the vaporized and residual polymers. GPC was conducted at $135^{\circ} \mathrm{C}$ with $1,2,4$-trichlorobenzene as the eluting solvent under a column condition of $250-10^{4}-$ $10^{5}$ so as to obtain a high separation efficiency 
in the molecular weight range of 100-10000. The calculation of the number-average molecular weight from the GPC chromatogram was done by the usual procedure. The peak was subdivided into intervals at every $1 \mathrm{~m} l$ of the elution volume.

The calibration plot was constructed using several $n$-paraffins and some standard polyethylene samples whose molecular weights were determined by ebulliometry.

The Ebulliometer used in this study was a Takara twin type, employing toluene as a solvent; this was purified by the ordinary method. The number-average molecular weight was calculated from the boiling-point elevation according to the usual method.

The Infrared Spectra of samples vaporized at $350^{\circ} \mathrm{C}$ and $400^{\circ} \mathrm{C}$ were measured to examine the thermal degradation, using a Hitachi PerkinElmer IR Spectrometer (Type 225). The absorption bands ascribed to the unsaturated bands $\left(900 \mathrm{~cm}^{-1}, 965 \mathrm{~cm}^{-1}, 990 \mathrm{~cm}^{-1}\right.$, and $\left.1635 \mathrm{~cm}^{-1}\right)$ were identified in the sample vaporized at $400^{\circ} \mathrm{C}$. On the other hand, no difference can be found between the spectra of the sample vaporized at $350^{\circ} \mathrm{C}$ and that of the original.

\section{RESULTS AND DISCUSSION}

\section{Effect of Vaporization Temperature}

Figure 2 shows typical chromatograms of the vaporized and residual polymers which were obtained after the vaporization experiment of the polyethylene sample (AC-615) at $340^{\circ} \mathrm{C}$ using the cell shown in Figure 1a. A sharp chromatogram of the vaporized polymer denotes a narrow molecular weight distribution, as in the case of Takizawa, et al. ${ }^{2}$ When the average molecular weights were computed from the GPC chromatogram, $M_{w} / M_{n}$ of the vaporized polymer at $340^{\circ} \mathrm{C}$ was found to be 1.08 . The characteristic narrow molecular weight distribution was observed until $380^{\circ} \mathrm{C}$; above $380^{\circ} \mathrm{C}$, the chromatogram gradually broadened towards the low molecular weight side with increasing temperature. The average molecular weights of the vaporized and the residual polymers, $M^{\nabla}$ and $M^{\mathrm{r}}$, are plotted in Figure 3 against the vaporization temperature. Here $M^{\mathrm{v}}$ and $M^{\mathrm{r}}$ were cal-

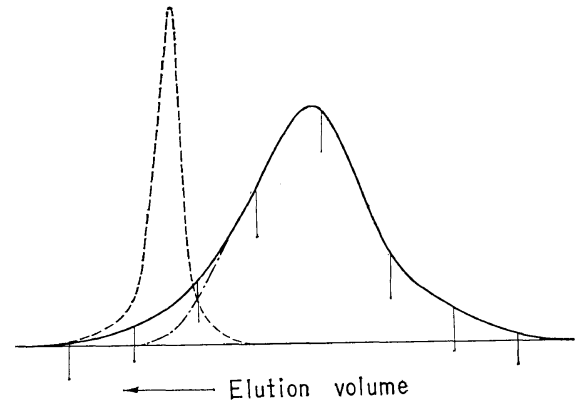

Figure 2. Typical GPC chromatogram for the polyethylene sample (AC-615): — - for the original sample; ----, for the vaporized sample at $340^{\circ} \mathrm{C} ; \cdot \cdots-$, for the residual sample at $340^{\circ} \mathrm{C}$.

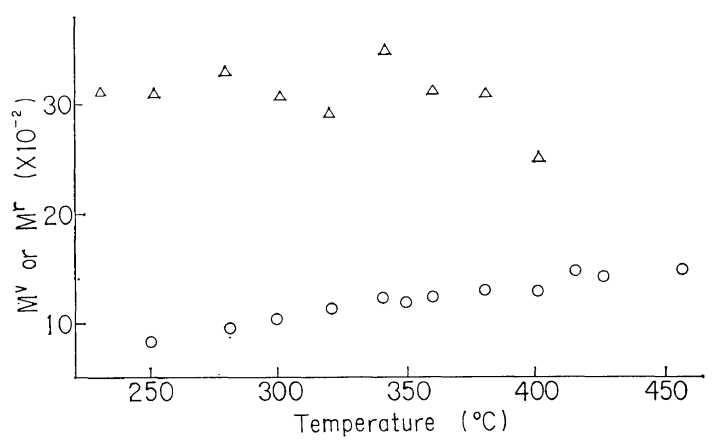

Figure 3. Relationship between the molecular weights of vaporized $M^{\mathrm{v}}$ and residual sample $M^{\mathrm{r}}$ (PE, AC-615) vs. the vaporization temperature. The molecular weights are calculated from the value of elution volume at the peak of GPC chromatogram: $\bigcirc, M^{\nabla}$, the molecular weight for the vaporized sample; $\triangle, M^{\mathrm{r}}$, the molecular weight for the residual sample.

culated from the peak count of the GPC chromatograms of the vaporized and the residual polymers, because the molecular weight at the peak count of the chromatogram is suitable for a direct comparison of the size of the eluted species in the case of a sample of narrow molecular weight distribution. It is remarkable that $M^{v}$ increases with increasing temperature of vaporization. For example, $M^{\vee}$ varies from 760 at $250^{\circ} \mathrm{C}$, to 1310 at $350^{\circ} \mathrm{C}$ and finally to 1500 at $420^{\circ} \mathrm{C}$, which correspond to the chain lengths of 54, 93, and 107, respectively. Meanwhile, $M^{\mathrm{r}}$ declines in relation to the temperature above $370^{\circ} \mathrm{C}$. In the case of Marlex-50, 


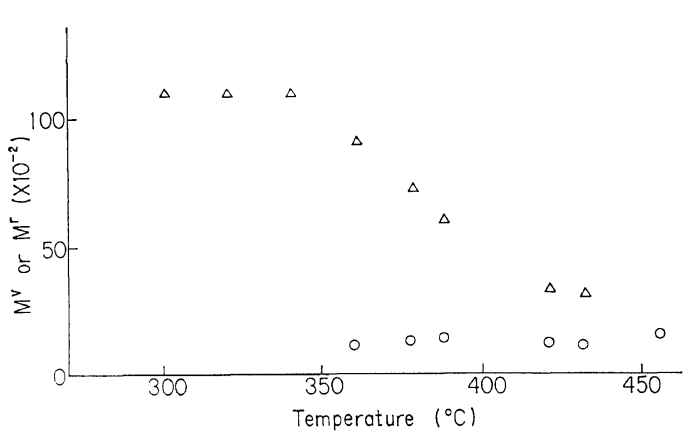

Figure 4. Relationship between the molecular weights of vaporized $M^{\mathrm{v}}$ and residual samples $M^{\mathrm{r}}$ (PE, Marex-50) vs. the vaporization temperature. The molecular weights are calculated from the value of elution volume at the peak of GPC chromatogram: $\bigcirc, M^{\nabla}$, the molecular weight for the vaporized sample; $\triangle, M^{\mathrm{r}}$, the molecular weight for the residual sample.

different results were found, as shown in Figure 4. It can be seen that no material evaporated until $360^{\circ} \mathrm{C}$ was reached, and that the molecular weight of the vaporized materials was nearly constant up to $460^{\circ} \mathrm{C}$. By comparing the GPC chromatogram of the original Marlex-50 with that of the vaporized materials, it was found that the two chromatograms were located at different positions. It is therefore clear that in the original sample the molecule which is capable of molecular vaporization below $360^{\circ} \mathrm{C}$ is not included. These results suggest that in the case of Marlex-50 the decomposed materials produced by thermal degradation play an important role in the vaporization process. This is confirmed in the behavior of the molecular weight of the residual polymer $\left(M^{\mathrm{r}}\right)$ in relation to the temperature: $M^{\mathrm{r}}$ decreases rapidly above $370^{\circ} \mathrm{C}$.

Comparison of the GPC Chromatogram of the

Original Sample with the Synthesized Patterns from the Vaporized pnd Residual Samples

The GPC chromatogram of the original polymer, AC-615, was compared with the patterns which were synthesized from the GPC diagrams of the vaporized and residual polymers, taking into account their weight fractions (Figure 5). The weight fractions of the vaporized and residual samples, $f^{v}$ and $f^{\mathrm{r}}$, were determined by experiments using the second type of cell (Figure 1b). As seen in the figure, the synthesized

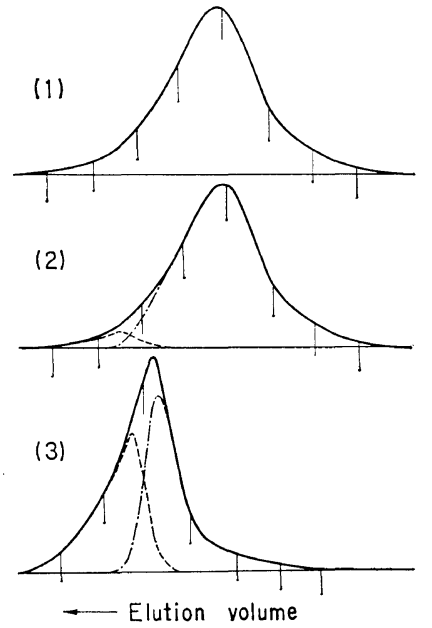

Figure 5. Change of the GPC chromatogram with the heating temperature in the polyethylene sample (AC-615): (1), the GPC chromatogram for the original sample; (2), the GPC chromatogram for the sample heated at $340^{\circ} \mathrm{C}\left(f^{\vee}=6.1 \%\right.$, $f^{r}=93.9 \%$ ); (3), the GPC chromatogram for the sample heated at $408^{\circ} \mathrm{C}\left(f^{\vee}=44.7 \%, f^{\mathrm{r}}=55.3 \%\right)$ : ----, the GPC chromatogram for the vaporized sample; -.-·, the GPC chromatogram for the residual sample; —_, the synthesized GPC chromatogram.

pattern at $340^{\circ} \mathrm{C}$ almost coincides with that of the original, while the pattern at $408^{\circ} \mathrm{C}$ is quite different. In Table I, the GPC molecular weight data are given for the various vaporization temperature, which were conducted using the second type of cell. Here $M_{n}{ }^{\nabla}$ and $M_{n}{ }^{\mathrm{r}}$ are the number-average molecular weights of the vaporized and residual polymers calculated from the respective GPC chromatograms. The changes of $M_{n}{ }^{\nabla}$ and $M_{n}{ }^{\mathrm{r}}$ with heating temperature do not show the same tendencies as in the case using the Madorsky type of cell (Figure 3). This is probably due to the difference of structure of the vaporization vessel employed. The total number-average molecular weight $\left(\bar{M}_{n}\right)_{\text {synth. }}$. given in the next to last column was calculated as follows:

$$
\frac{1}{\left(\bar{M}_{n}\right)_{\text {synth. }}}=\frac{f^{\mathrm{v}}}{M_{n}^{\mathrm{v}}}+\frac{f^{\mathrm{r}}}{M_{n}^{\mathrm{r}}}
$$

$\left(\bar{M}_{n}\right)_{\text {obsd. }}$ in the last column was obtained from the GPC chromatogram of the mixed solution of the vaporized and the residual polymer 
Table I. Number-average molecular weight, observed and calculated from the synthesized GPC chromatogram at various vaporization temperatures

\begin{tabular}{|c|c|c|c|c|c|c|c|}
\hline$\underset{{ }^{\circ} \mathbf{C}}{\operatorname{Temp}}$ & $\underset{\text { min }}{\text { Duration time, }}$ & $\begin{array}{l}M_{n}^{\nabla} \\
\times 10^{-2}\end{array}$ & $f_{\%}^{v}$ & $\begin{array}{l}M_{n}^{\mathrm{r}} \\
\times 10^{-2}\end{array}$ & $f_{\%}^{\mathrm{r}}$ & $\begin{array}{l}\left(\bar{M}_{n}\right)_{\text {synth. }} \\
\quad \times 10^{-2}\end{array}$ & $\begin{array}{l}\left(\bar{M}_{n}\right)_{\text {obsd }}, \\
\quad \times 10^{-2}\end{array}$ \\
\hline 303 & 30 & 6.6 & 5.8 & 30.1 & 94.2 & 25.0 & 29.0 \\
\hline 325 & 60 & 9.7 & 8.1 & 39.0 & 91.9 & 31.3 & 25.5 \\
\hline 340 & 40 & 8.0 & 6.1 & 32.6 & 93.9 & 28.0 & 27.6 \\
\hline 344 & 40 & - & - & - & - & - & 29.3 \\
\hline 353 & 30 & 7.0 & 5.0 & 28.4 & 95.0 & 24.7 & 29.2 \\
\hline 362 & 30 & - & - & - & - & - & 25.0 \\
\hline 374 & 30 & 7.8 & 23.7 & 27.2 & 76.3 & 17.1 & 14.3 \\
\hline 408 & 30 & 7.3 & 44.7 & 14.8 & 55.3 & 10.1 & 9.3 \\
\hline 420 & 30 & 7.2 & 95.1 & 15.0 & 4.9 & 7.3 & 9.0 \\
\hline
\end{tabular}

samples as a whole. From Table I, it can be seen that under $370^{\circ} \mathrm{C},\left(\bar{M}_{n}\right)_{\text {synth. }}$ and $\left(\bar{M}_{n}\right)_{\text {obsd. }}$. are almost equal to the molecular weight of the original sample AC-615 $\left(M_{n}=2800\right)$, but that beyond $370^{\circ} \mathrm{C}$ these values decrease with increasing temperature. These results show that evaporation of the sample at temperatures under $370^{\circ} \mathrm{C}$ would be due to distillation from the mixed hydrocarbon, without any thermal degradation, and that evaporation above $370^{\circ} \mathrm{C}$ would include some processes of thermal degradation of the original sample.

Analysis of Volatile Substances Vaporized above $400^{\circ} \mathrm{C}$

In analysing the data obtained with the second type of cell, the amounts of volatile products obtained under the respective experimental conditions were determined by subtracting the sum of vaporized and residual polymers $\left(W^{\mathrm{v}}+W^{\mathrm{r}}\right)$ from the amounts of the original sample AC-615 $\left(W^{\circ}\right)$. Figure 6 shows a plot of the percentage

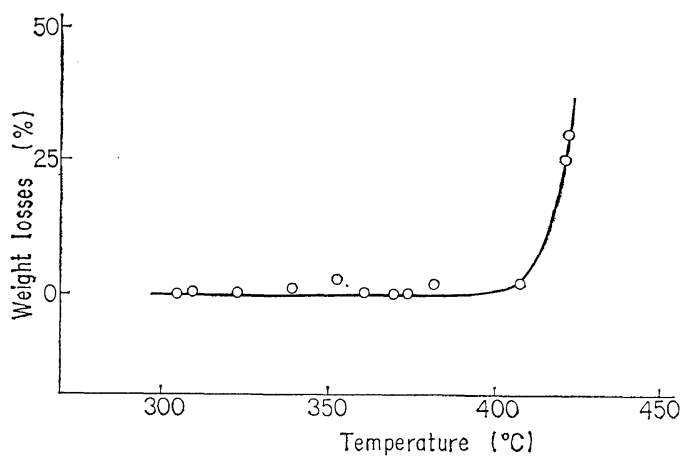

Figure 6. Relationship between the percentage losses and the heating temperature (PE, AC-615). weight losses, $\left(1-\left(W^{\nabla}+W^{\mathrm{r}}\right) / W^{\circ}\right) \times 100$, in relation to the heating temperature. From this figure, it can be seen that the weight loss due to the volatile product is nearly negligible up to $400^{\circ} \mathrm{C}$ and that above that temperature it becomes significant. It is suggested that although the degradation of the sample starts at $370^{\circ} \mathrm{C}$ (Figure 6), only moderate fragments are yielded up to $410^{\circ} \mathrm{C}$.

Comparison with Kurata's and Simha's theories

According to the relationship between the boiling temperature $\left(T_{\mathrm{b}}\right)$ and the number of carbon atoms of $n$-paraffins established by Kurata, et al., ${ }^{6}$ based on the hole theory of liquids, the boiling temperature of each $n$-paraffin is given as follows:

$$
T_{\mathrm{b}}=\frac{n^{2 / 3}}{A+B \cdot n^{2 / 3}}
$$

Where $T_{\mathrm{b}}$ is the boiling temperature $(\mathrm{K}), n$ is the number of carbon atoms, $A=0.00784-0.00215 \times$ $\log P-0.00010 \times(\log P)^{2}, \quad$ and $B=0.0005514-$ $0.000011 \times \log P$, in which $P$ is the pressure (atm).

We tried to analyse our experimental data for the vaporization of polyethylene oligomer using eq 2 , though the validity of the equation has not yet been examined in such a high vacuum as in the present case. The results are shown in Figure 7. Here, the full line represents the theoretical curve calculated from the Kurata's equation for our experimental condition $\left(P=5 \times 10^{-7} \mathrm{mmHg}\right)$. The experimental data are represented by closed circles, where the number of carbon atoms are calculated from the GPC chromatogram of vaporized polymer at each temperature $\left(T_{\mathrm{b}}\right)$. Further, for comparison with the experimental 


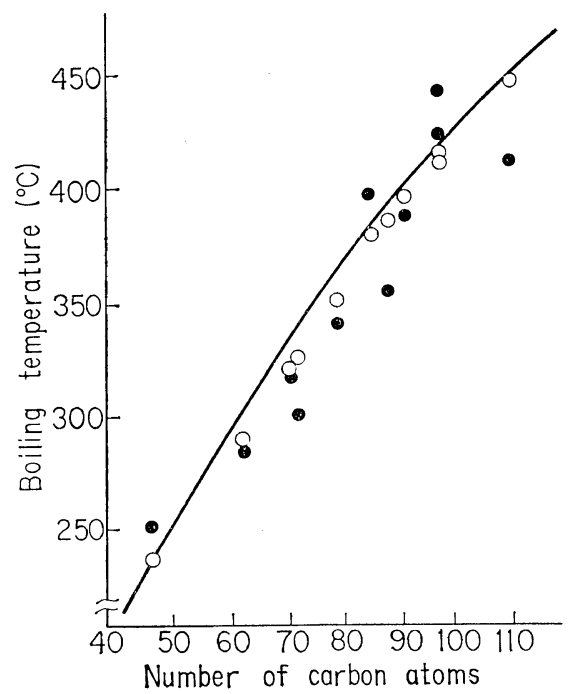

Figure 7. Relationships between the boiling temperature $\left(T_{\mathrm{b}}\right)$ and the number of carbon atoms: - relation $T_{\mathrm{b}} v s$. number of carbon atoms calculated by Kurata's equation at $P=5 \times 10^{-7}$ $\mathrm{mmHg}$; - relation of $T_{\mathrm{b}}$ (obsd) vs. average number of carbon atoms; $\bigcirc$, relation of $T_{\mathrm{b}}$ (calcd) $v s$. average number of carbon atoms.

boiling temperature, the theoretical boiling temperature $\left(\bar{T}_{\mathrm{b}}\right)$ for the vaporized polymer is calculated using the following equation, under the assumption that the multicomponent system vaporized is an ideal mixture:

$$
\bar{T}_{\mathrm{b}}=\frac{\sum f_{i} \times T_{\mathrm{b} i}}{\sum f_{i}}
$$

Here $f_{i}$, which is the weight fraction denoting the relative number of the $i$-th molecule in the system, is evaluated from the GPC chromatogram of the respective vaporized polymer. $T_{\mathrm{b} i}$ is the boiling temperature calculated from the Kurata's equation for the $i$-th molecule. As shown in the figure, the experimental and calculated points nearly coincide. It is interesting to notice that the coincidence between the two boiling temperatures continues into the temperature range that induces the thermal decomposition of the polymer. From these results, it is shown that the Kurata's equation of state for $n$-paraffin liquids exactly establishes the boiling temperature of a multicomponent system with a high molecular weight.

Since it has been confirmed that above $370^{\circ} \mathrm{C}$ the evaporation process brings about some decomposition of the sample, a complete kinetic analysis of the process should take into account the simultaneous processes of degradation and evaporation. According to the analysis of Simha, et al ${ }^{4}$ for such a complicated process, the removal of smaller molecules by molecular distillation from the reacting mixture modifies the depolymerization kinetics. In other words, the molecular weight of the remaining sample decreases less rapidly and tends to a limiting value, depending on the maximum size of the evaporating molecule, which is called the "critical chain length $(L)$ ". The number-average degree of polymerization $\left(\overline{\boldsymbol{P}}_{n}^{\mathrm{r}}\right)$ of the remaining sample is represented as follows:

$$
\bar{P}_{n}{ }^{\mathrm{r}}=\frac{n+\alpha(n-L)(L-1)}{1+\alpha(n-L)}
$$

Here $n$ is the initial degree of polymerization of the sample and $\alpha$ represents the fraction of total number of linkages broken at a given stage of depolymerization. The above relation shows that in the limiting case of $\alpha=1$, which is realized in practice by continuing the vaporization to a high conversion, $\bar{P}_{n}{ }^{\mathrm{r}}$ will approach the value of the critical chain length $(L)$. The condition of our vaporization experiment conducted at a high temperature, e.g., at $420^{\circ} \mathrm{C}$, seems to be in accord with the limiting case. This is because vaporization at $420^{\circ} \mathrm{C}$ was continued to a high conversion of $95 \%$, and the GPC chromatogram of the remaining sample showed a narrow molecular weight distribution. So it can be assumed that $\bar{P}_{n}{ }^{\mathrm{r}}=107\left(M_{n}^{\mathrm{r}}=1500\right)$ at $420^{\circ} \mathrm{C}$ is the critical chain length " $L$ " of the polyethylene molecule under the present experimental conditions.

Furthermore, according to Simha's analysis for the distribution of the evaporated material in the trap, the number- and weight-average degrees of polymerization of the vaporized sample, $\bar{P}_{n}{ }^{\vee}$ and $\bar{P}_{w} v$, are related to $L$ as follows:

$$
\bar{P}_{n}{ }^{\vee}=L / 2, \quad \bar{P}_{w}{ }^{\vee}=(1 / 3)(2 L-1)
$$

These relations also enable an experimental evaluation to be made for $L$. From the GPC chromatogram of the sample evaporated at $420^{\circ} \mathrm{C}$, one can calculate $\bar{P}_{n}{ }^{v}=720 / 14$ and hence $L=103$ is determined, though the value is overestimated 
by neglecting the volatile product produced by the decomposition of the sample. This $L$-value agrees, within the margin of experimental error, with $L=107$ obtained from the previous considerations. Consequently, it is shown that Simha, et al.'s analysis in depolymerization kinetics provide a satisfactory explanation of the phenomena observed in the high temperature range of the vaporization of polyethylene oligomers.

\section{REFERENCES}

1. Y. Miyoshi, K. Takahashi, and N. Saito, Rep.
Progr. Polym. Phys. Japan, 10, 213 (1967); Y. Miyoshi and K. Chino, Japan. J. Appl. Phys., 6, 181 (1967).

2. T. Takizawa, Y. Takano, C. Shibuya, and S. Hayashi, Rep. Progr. Polym. Phys. Japan, 11, 237 (1968).

3. S. L. Madorsky, S. Straus, D. Thompson, and L. Williamson, J. Polym. Sci., 4, 639 (1949).

4. R. Simha and L. A. Wall, ibid., 6, 39 (1951).

5. L. A. Wall, J. H. Flynn, and S. Straus, J. Phys. Chem., 74, 3237 (1970).

6. M. Kurata and S. Ishida, J. Chem. Phys., 23, 1126 (1955); K. Nakanishi, M. Kurata, and M. Tamura, J. Chem. Eng. Data, 38, 67 (1964).

7. E. J. Slowinski, Jr., H. Walter, and R. E. Miller, J. Polym. Sci., 19, 353 (1956). 